\title{
Declarações de Acesso Aberto e a Lei de Direitos Autorais brasileira
}

\author{
Declarations of Open Access and the Brazilian Copyright Law
}

\section{Declaraciones de Acceso Abierto y la Ley de Derechos de Autor brasileña}

\author{
Rebeca de Moura Andrade | rebeca.andrade@ufsc.br \\ Universidade Federal de Santa Catarina, Programa de Pós-Graduação em Ciência da Informação. Florianópolis, Brasil. \\ Enrique Muriel-Torrado | enrique.muriel@ufsc.br \\ Universidade Federal de Santa Catarina, Programa de Pós-Graduação em Ciência da Informação. Florianópolis, Brasil.
}

\section{Resumo}

O Acesso Aberto é conhecido como um movimento que visa democratizar o conhecimento na sociedade, deixando este, passível de ser consultado facilmente pelos usuários. Nesse sentido, documentos como as três declarações (3 Bs ou BBB - Budapeste, Bethesda e Berlim) objetivam incentivar e compartilhar práticas e discussões a respeito do acesso aberto. Em contrapartida, o Brasil também conta com instituições e dispositivos legais, como a lei ${ }^{0}$ 9.610, de 19 de fevereiro de 1998, que objetiva consolidar e regularizar os direitos autorais. Neste artigo, discute-se as três declarações fundamentais do movimento (3 Bs) e sua relação com a lei de Direitos Autorais, para comprovar se existe uma convergência ou divergência entre o espírito das declarações e a lei. Como conclusão, percebe-se que a lei de Direitos Autorais não engloba todas as necessidades conferidas pelo movimento. Desta forma, busca-se alternativas para proteger os autores e ao mesmo tempo oferecer aos usuários alguns direitos.

Palavras-chave: Acesso Aberto; Declarações; Direito Autoral; Direito à informação; Propriedade Intelectual.

\begin{abstract}
Open Access is known as a movement that aims to democratize knowledge in society, making it easily consulted by the users. On this matter, documents such as the three statements (3 Bs or BBB - Budapest, Bethesda and Berlin) aim to encourage and share practices and discussions regarding open access. On the other hand, Brazil also has legal institutions and provisions, such as Law No. 9610 of February 19, 1998, which aim is to consolidate and regularize copyright. In this article, we discuss the three fundamental declarations of the movement ( $3 \mathrm{Bs}$ ) and its relation with the Copyright Law, to verify if there is a convergence or divergence between the spirit of the declarations and the law. As a conclusion, the Copyright Law does not cover all the needs stated by the movement. In this way, alternatives are sought to protect authors and at the same time offer users some rights.
\end{abstract}

Keywords: Open Access; Statements; Copyright; Right to information; Intellectual Property. 


\section{Resumen}

El acceso abierto es conocido como un movimiento que pretende democratizar el conocimiento en la sociedad, facilitando que los usuarios lo tengan a su disposición. En ese sentido, las tres declaraciones principales de Accesso Abierto (3 Bs o BBB - Budapest, Bethesda y Berlín) tienen como objetivo incentivar y compartir prácticas y discusiones sobre el Open Access. Por su parte, Brasil cuenta con instituciones y dispositivos legales, como la ley 9.610, de 19 de febrero de 1998, que pretende consolidar y regularizar los derechos de autor. En este artículo se discuten las tres declaraciones fundamentales del movimiento (3 Bs) y su relación con la ley de Derechos de Autor, para comprobar si existe una convergencia o divergencia entre el espíritu de las declaraciones y la ley. Como conclusión, se percibe que la ley de Derechos de Autor no engloba todas las necesidades del movimiento para disponibilizar la información. De esta forma, se buscan alternativas para proteger a los autores y al mismo tiempo ofrecer a los usuarios algunos derechos, imprescindibles para el movimiento.

Palabras-clave: Acceso abierto; Declaraciones; Derechos de Autor; Derecho a la información; Propiedad Intelectual.

\section{Proposta}

O movimento de Acesso Aberto ou Open Access (OA) é definido como um movimento que está ligado à disponibilização aberta da informação, sem restrição de acesso, seja via meio eletrônico ou pela concessão de cópias impressas para qualquer finalidade. Trata-se da liberação da divulgação de resultados científicos em espaços abertos, em contraposição com o modelo restrito de comunicação científica, representado entre outros, pelas grandes bases de dados que impõem um pagamento para acessar às obras. A ideia subjacente é que autores e leitores tenham acesso as pesquisas de terceiros, sem que o dinheiro seja uma barreira ${ }^{1}$.

No Brasil é possível encontrar periódicos científicos, recursos educativos ou repositórios de Acesso Aberto, entre outros, como por exemplo a plataforma SciELO', que foi “[...] lançada para aumentar a visibilidade de publicações científicas brasileiras que, até o século passado, estavam escassamente indexadas em bases de dados internacionais”. ${ }^{2}$. Esta é uma das iniciativas brasileiras que promovem e se dedicam a disponibilizar informação científica para toda a comunidade.

Contudo, a regulação da autoria destas obras está regida, no Brasil, pela lei de Direitos Autorais $\mathrm{n}^{0}$ 9.610, de 19 de fevereiro de 1998, que altera, atualiza e consolida a legislação sobre direitos autorais³.

O objetivo deste trabalho é trazer a discussão das três declarações fundamentais do movimento (BBB: Budapeste, Bethesda e Berlim) e sua relação com a lei de Direitos Autorais de 1998, para comprovar se existe uma convergência ou divergência entre o espírito das declarações e a lei.

\section{As declarações de Acesso Aberto: Budapeste, Bethesda e Berlim}

Baseadas na promoção e no alcance irrestrito à informação científica, têm-se como objeto de estudo as três declarações fundamentais, também conhecidas por 3 Bs ou BBB: Budapeste, Bethesda e Berlim. Tais documentos, escritos entre os anos de 2001 a 2003, são importantes fontes de discussão sobre acesso aberto nas mais variadas áreas de conhecimento.

A Declaração de Budapeste 4 , é um dos principais documentos norteadores, e apresenta uma ampla possibilidade de acesso e usos das obras. Para explicar sobre o movimento, alguns autores ${ }^{1}$, fazem referência à Declaração de Budapeste como a disponibilização gratuita das obras criadas na internet, possibilitando que as pessoas leiam, copiem, imprimam, ou que utilizem a obra com qualquer propósito. A Declaração de Budapeste cita uma única barreira ao uso irrestrito da informação: o copyright.

i http://www.scielo.org 
Neste sentido, o copyright se apresenta como um fator restritivo limitando as possibilidades de uso das obras, isto significa uma barreira para o movimento.

Entretanto, em relação à pesquisa e ao ensino o acesso aberto tem como objetivo a quebra dessas barreiras, liberando o uso para propósitos acadêmicos, o que converge com os princípios das três declarações ${ }^{1}$.

A Declaração de Bethesda ${ }^{5}$, é desenvolvida por uma diversa gama de expertises como pesquisadores, cientistas ou editores entre outros, com o intuito de assegurar o acesso livre a literatura científica, especificamente a informação na área biomédica. Nela destaca que para ser considerado OA é preciso ofertar uma cópia da obra em repositórios abertos e ainda:

"O autor (es) e titular de direitos de autor (s) de concessão (s) a todos os utilizadores um livre irrevogável mundial direita, perpétuo de acesso e uma licença para copiar, usar, distribuir, transmitir e exibir o trabalho publicamente e fazer e distribuir trabalhos derivados, em qualquer meio digital para qualquer propósito responsável, sujeito à correta atribuição da autoria [2], bem como o direito de fazer um pequeno número de cópias impressas para seu uso pessoal."

Isto é, se assegura que os autores concedam os direitos necessários para que as obras sejam disponibilizadas com uma série de condições, como permitir sua cópia, compartilhamento, etc.

Já a Declaração de Berlim ${ }^{6}$, escrita por pesquisadores de universidades europeias, trata sobre o acesso livre ao conhecimento com foco nas ciências e humanidades. Tal conhecimento é caracterizado como universal e parte do alicerce científico.

O documento ${ }^{6}$ apresenta duas diretrizes para as contribuições de livre acesso. A primeira, zela pela concessão completa de todos os direitos dos autores, com imposição de uso responsável, por meio de “[...] uma licença para copiar, usar, distribuir, transmitir e exibir o trabalho publicamente e realizar e distribuir obras derivadas, em qualquer suporte digital para qualquer propósito responsável [...]”. A segunda descreve o formato da obra, que deve ser completo e disponível em repositórios adequados às normas técnicas, de forma a garantir o irrestrito acesso, além de incluir:

“[...] uma cópia da licença como acima definida, é depositada (e portanto publicada) num formato electrónico normalizado e apropriado em pelo menos um repositório que utilize normas técnicas adequadas (como as definições Open Archive) que seja mantido por uma instituição académica, sociedade científica, organismo governamental ou outra organização estabelecida que pretenda promover o acesso livre, a distribuição irrestrita."

A missão, o espírito das declarações, é disseminar o conhecimento deixando disponível em larga escala e sem as restrições que, como se verá a continuação, impõe à legislação de direitos autorais. Sem a expansão deste conhecimento e, por sua vez, sem tornar a informação acessível à sociedade tal missão estará incompleta.

\section{Lei brasileira de Direitos Autorais}

Promulgada em 1998, a lei atualizou os dispostos na Lei No 5.988, de 14 de dezembro de 1973, até então responsável por regulamentar os direitos autorais.

Os Direitos Autorais, também conhecidos como copyright, são entendidos como "todos os direitos reservados" e tem como objetivo proteger o autor da obra. São representados pela letra C circunscrita: (C), embora ou seu uso não seja obrigatório. A proteção é regulada através da lei 9.610/98 que gere os Direitos Autorais no Brasil e dispõe acerca da autoria das obras intelectuais. 
Um dos principais conflitos entre as Declarações de Acesso Aberto e a Lei são os direitos patrimoniais (arts. 28-45). O artigo 29 da lei ${ }^{3}$ concede aos autores o controle sobre suas obras, obrigando as pessoas que queiram usá-las a solicitar uma permissão ao titular dos direitos:

"Art. 29. Depende de autorização prévia e expressa do autor a utilização da obra, por quaisquer modalidades, tais como:

I - a reprodução parcial ou integral;

II - a edição;

III - a adaptação, o arranjo musical e quaisquer outras transformações;

IV - a tradução para qualquer idioma;

$\mathrm{V}$ - a inclusão em fonograma ou produção audiovisual;

VI - a distribuição, quando não intrínseca ao contrato firmado pelo autor com terceiros para uso ou exploração da obra;

VII - a distribuição para oferta de obras ou produções mediante cabo, fibra ótica, satélite, ondas ou qualquer outro sistema que permita ao usuário realizar a seleção da obra ou produção para percebê-la em um tempo e lugar previamente determinados por quem formula a demanda, e nos casos em que o acesso às obras ou produções se faça por qualquer sistema que importe em pagamento pelo usuário;

VIII - a utilização, direta ou indireta, da obra literária, artística ou científica, mediante. [...] IX - a inclusão em base de dados, o armazenamento em computador, a microfilmagem e as demais formas de arquivamento do gênero;

$\mathrm{X}$ - quaisquer outras modalidades de utilização existentes ou que venham a ser inventadas."

Os principais conflitos entre a lei e as Declarações são aqueles que atingem à reprodução das obras (I), que se produz por exemplo, quando fazemos download de um artigo científico desde um portal de periódicos ou quando fazemos uma cópia de um arquivo em PDF. No caso das traduções das obras, são reguladas pelo inciso IV, que obriga a solicitar permissões para poder fazê-las.

A distribuição (VII) acontece, por exemplo, quando compartilhamos uma obra por e-mail. Neste último processo também afeta ao direito de reprodução, já que fazemos uma cópia do arquivo original para anexálo ao e-mail e quando é recebido pelo destinatário baixa uma cópia do arquivo em seu dispositivo. Por outro lado (IX), também é comum que um artigo submetido em uma revista esteja de forma direta ou indireta incluído em uma base de dados.

No contexto do acesso aberto não teria sentido solicitar permissões ao titular ou titulares dos direitos para exercer algumas das atividades que são claramente o foco do movimento: acessar as informações, baixar os artigos (reprodução), a possibilidade de fazer traduções e compartilhar com terceiros a través da rede (distribuição).

\section{Conclusão}

A lei de direitos autorais brasileira, por si mesma, não contempla as necessidades do movimento OA, particularmente no referido à reprodução, tradução e compartilhamento da informação científica, nem mediante as exceções e limitações recolhidas no Capítulo IV da lei.

Por este motivo surgiram alternativas complementares que ajudam a proteger aos autores ao mesmo tempo que oferece aos usuários alguns direitos. Isto se articula principalmente mediante as licenças Creative Commons, que permitem que os autores possam compartilhar os direitos que considerem oportunos e se reservar outros.

Os documentos utilizados para estudo neste trabalho tratam da disponibilização do conhecimento e dos direitos autorais. Entretanto, a lei é um meio, acionado por interessados em resguardar o direito autoral, enquanto as declarações incentivam e instruem toda a comunidade ao compartilhamento de pesquisas, como forma mundial de difusão dos conhecimentos. 
Verificados os mecanismos legais de proteção dos direitos autorais e dos princípios e valores relacionados ao acesso aberto conclui-se que a lei por si mesma não é suficiente para efetivar o movimento, precisando do complemento das licenças Creative Commons para poder atingir seus objetivos.

\section{Referências}

1. Suber, P. Open Access. United States of American: MIT Press; 2012 [acesso em 2017 abr 18]. Disponível em: https://mitpress.mit.edu/sites/default/files/9780262517638 Open Access PDF Version.pdf

2. Marques, F. O futuro do acesso aberto. Pesquisa FAPESP. 2016 jul [acesso em 2017 abr 14]; 245:30-33. Disponível em: http://revistapesquisa.fapesp.br/wp-content/uploads/2016/07/030 Acesso-aberto 245. pdf?349dcc

3. Brasil. Lei no. 9.610, de 19 de fevereiro de 1998. Altera, atualiza e consolida a legislação sobre direitos autorais e dá outras providências. Diário Oficial da União 20 fev 1998. Disponível em: http://www. planalto.gov.br/ccivil 03/leis/L9610.htm

4. Read the Budapeste open access iniciative. Budapeste open access initiative, Hungria, 2002 [acesso em 2017 abr 15]. Disponível em: http://www.budapestopenaccessinitiative.org/read

5. Bethesda Declaração sobre a publicação de acesso aberto. 2003 [acesso 2017 abr 15]. Disponível em: http://www.autoersatzteile.de/blog/bethesda-declaracao-sobre-a-publicacao-de-acesso-aberto

6. Berlin declaration on open access to knowledge in the sicence and humanities. Open Access MaxPlanck-Gesellschaft, 2003 [acesso em 2017 mar 17]. Disponível em: https://openaccess.mpg.de/BerlinDeclaration 